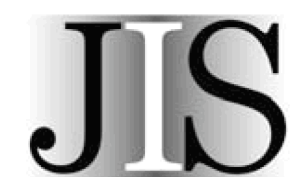

\title{
The Knowledge Pyramid: A Critique of the DIKW Hierarchy
}

This paper has been accepted for publication in Journal of Information Science and the final (edited, revised and typeset) version of this paper will be published in Journal of Information Science Vol?/Issue?/Year? By SAGE Publications Ltd.. All rights reserved. (C) CILIP. For more information please visit: http://jis.sagepub.co.uk

\author{
Martin Frické \\ School of Information Resources and Library Science, The University of Arizona, Tucson, Arizona, AZ 85718, USA
}

\begin{abstract}
The paper evaluates the Data-Information-Knowledge-Wisdom (DIKW) Hierarchy. This hierarchy is part of the canon of information science and management. The paper considers whether the hierarchy, also known as the 'Knowledge Hierarchy', is a useful and intellectually desirable construct to introduce, whether the views expressed about DIKW are true and have evidence in favour of them, and whether there are good reasons offered or sound assumptions made about DIKW. Arguments are offered that the hierarchy is unsound and methodologically undesirable. The paper identifies a central logical error that DIKW makes. The paper identifies the dated and unsatisfactory philosophical positions of operationalism and inductivism as the philosophical backdrop to the hierarchy. The paper concludes with a sketch of some positive theories, of value to information science, on the nature of the components of the hierarchy: that data is anything recordable in a semantically and pragmatically sound way, that information is what is known in other literature as 'weak knowledge', that knowledge also is 'weak knowledge' and that wisdom is the possession and use, if required, of wide practical knowledge, by an agent who appreciates the fallible nature of that knowledge.
\end{abstract}

Keywords data; information; knowledge; wisdom, the DIKW Hierarchy, the Knowledge Hierarchy, the Knowledge Pyramid. 


\section{Martin Frické}

\section{Introduction}

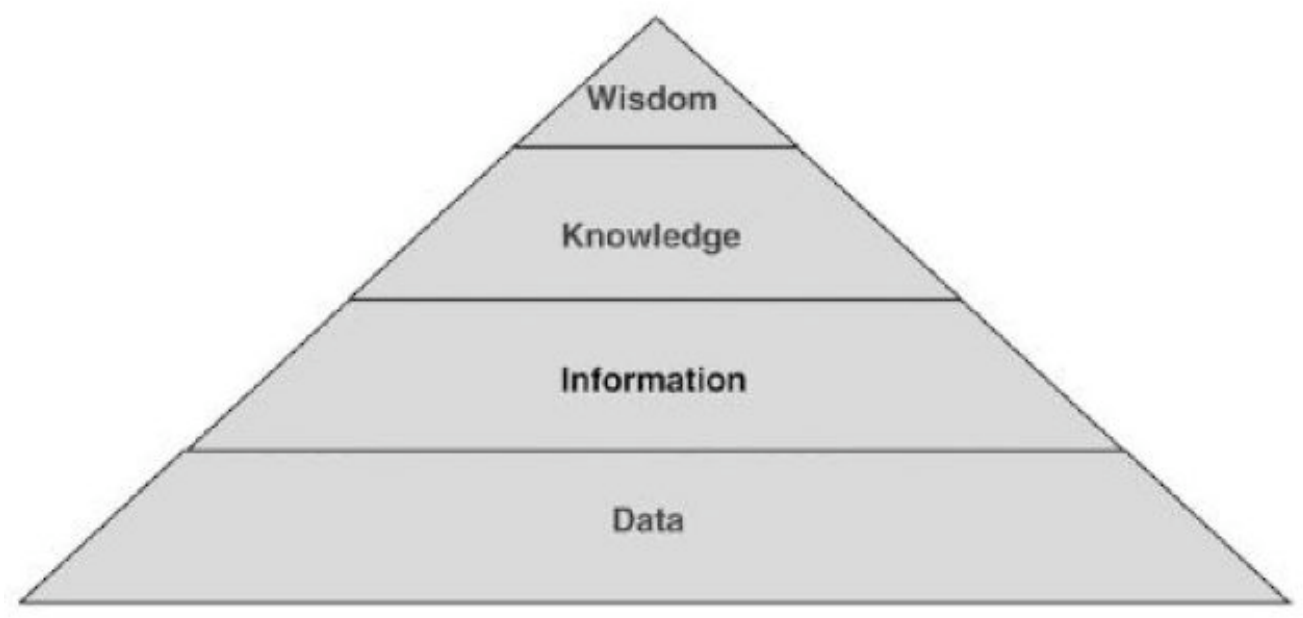

Many theoreticians, in Computer Science, Management Information Systems and in Librarianship, see information in terms of a data-information-knowledge-wisdom (DIKW) hierarchy or pyramid [1] [2].

As Rowley writes

The hierarchy referred to variously as the 'Knowledge Hierarchy', the 'Information Hierarchy' and the 'Knowledge Pyramid' is one of the fundamental, widely recognized and 'taken-for-granted' models in the information and knowledge literatures. It is often quoted, or used implicitly, in definitions of data, information and knowledge in the information management, information systems and knowledge management literatures.... [1]

Rowley [1] offers a detailed exegesis of just how widespread this view is, and of the similarities and differences between the writers' statements. (There also has been a wide-ranging discussion on the JESSE listserv [3].) The present paper aims to complement this work. The targets here are the questions of whether DIKW is a useful and intellectually desirable construct to introduce, whether the views expressed about DIKW are true and have evidence in favour of them, and whether there are good reasons offered or sound assumptions made about DIKW. In brief, is DIKW an intellectually attractive prospect?

The answer to be defended here is that the DIKW pyramid should be abandoned. It should no longer be part of the canon of information science, and such related disciplines as systems theory, information management, information systems, knowledge management, and library and documentation science. Discarding DIKW would leave an intellectual and theoretical vacuum over the nature of data, information, knowledge, and wisdom, and their interrelationships, if any. This paper does not attempt to replace the pyramid with another structure. It does, though, offer some positive suggestions on the nature of data, information, knowledge, and wisdom. These concepts, certainly the first three, are part of the common currency of information science. Thus, the paper attempts to advance debate on the theoretical underpinnings of information science.

\section{What is DIKW?}

As Rowley's work testifies, there are genuine and possibly substantive differences in view about DIKW and its properties. Nevertheless, there is a core, and sufficient similarities in view for a position to be extracted and scrutinized. The main views are perhaps best expressed in the traditional sources of Adler, Ackoff and Zeleny [4-6]. 


\section{Martin Frické}

What, at the heart, is DIKW and how does it work? It is suggested that there is a hierarchy built on the foundation of data [4], p 3.

Wisdom is located at the top of a hierarchy of types .... Descending from wisdom there are understanding, knowledge, information, and, at the bottom, data. Each of these includes the categories that fall below it... ([4],p 3)

[Ackoff includes a fifth level, "understanding"; typically, that is not done.]

It is supposed that the many and various items of the world have properties that can be observed. And data is the symbolic representation of these observable properties ([1] Section 5.2 Defining Data). The prime example of data and data acquisition is provided by automatic instrument systems; an unmanned weather station, for instance, may record daily maximum and minimum temperatures; such recordings are data. Ackoff writes

Data are symbols that represent properties of objects, events and their environments. They are products of observation. To observe is to sense. The technology of sensing, instrumentation, is, of course, highly developed. ([4] p.3)

The acquisition of data can be generalized well beyond automatic instruments. When, for example, a person fills in a form giving their name, address, age, social security number-- these inscriptions are data. (Actually, the term "raw data" seems apposite.)

Next up the hierarchy is information. This is relevant, or usable, or significant, or meaningful, or processed, data ([1] Section 5.3 Defining Information). The vision is that of a human asking a question beginning with, perhaps, "who", "what", "where", "when", or "how many" ([4] p.3); and the data is processed into an answer to an enquiry. When this happens, the data becomes "information". Data itself is of no value until it is transformed into a relevant form. In consequence, the difference between data and information is functional, not structural ([4] p.3).

Information can also be inferred from data-- it does not have to be immediately available. For example, were an enquiry to be "what is the average temperature for July?"; there may be individual temperatures explicitly recorded as data, but perhaps not the average temperature; however, the average temperature can be calculated or inferred from the data about individual temperatures. The processing of data to produce information often reduces that data (because, typically, only some of the data is relevant). Ackoff writes

Information systems generate, store, retrieve, and process data. In many cases their processing is statistical or arithmetical. In either case, information is inferred from data. ([4] p.3)

Information is relevant data, together with, on occasions, the results of inferences from that relevant data. Information is thus a subset of the data, or a subset of the data augmented by additional items inferred or calculated or refined from that subset.

The next category is knowledge. Users of this hierarchy often construe knowledge as know-how, or skill, rather than knowledge in the sense of the know-that of propositional knowledge. (Some explanation is perhaps in order. Knowledge, in the sense of a knowledge base or knowledge within traditional philosophy, is just a collection of "know-thats" for example, a person might know that the Eiffel Tower is in Paris and know that the Channel Tunnel connects England and France. Additionally, using the different concept, that very same person might know how to ride a bicycle. This latter is a different kind of knowledge, it is skill or "know-how"[7].) Ackoff suggests that know-how allows an agent to promote information to a controlling role-- to transform information into instructions. For example, data as to a room's temperature might become information when an agent asks "what is the temperature?" and, in turn, that information can become instructions to turn the air conditioner on, if the agent appreciates the way the temperature of the room is controlled-- the information, in this case, transitions into knowledge-how-tocool.

Further up the hierarchy comes wisdom - a category which is given only limited discussion in the present paper. There are two immediate points to be made about wisdom. While wisdom is traditionally taken to be a layer in the hierarchy, few authors discuss it or use it. This may be because it is not required for the problems they address. (See [1].) Second, criticisms offered in this paper will undermine the 


\section{Martin Frické}

foundational layers, so a successful account of wisdom, whatever nature that might have, will not place it as an upper layer in the DIKW hierarchy.

\section{How sound or desirable is this hierarchy?}

Centrally, how sound is the view of information?

As a preliminary, let us be clear over the key notion of "truth" (for truth permeates these discussions). What the DIKW theorists use, and what is subscribed to in this paper, is the common-sense or objective view of truth. It places contingent truth as a correspondence between statements or beliefs or thoughts or sentences or propositions, and the world $[8,9]$. So, for example, the statement that there are crocuses in Kew Gardens is true if, indeed, in the world, there are crocuses in Kew Gardens. This simple idea is widely accepted: it is for example the one used in a Court of Law (for instance, to assert that testimony is true, in a Court, is to assert that the testimony describes the way things are).

Data in the DIKW theory amounts to, or correspond to, little more than low-level true factual statements (to empirical statements known to be true by observation). Automatic instrument systems are the exemplar. So, for example, if there is some data about, say, the daily maximum temperature, it might be represented, by some statements; namely

Day 1 has maximum temperature 82 degrees.

Day 2 has maximum temperature 80 degrees.

Day 3 has maximum temperature 83 degrees.

and these statements, like all statements, are going to be true or false. And for "data" in the sense used here, the statements will have to be true. (Inaccurate or mistaken data is not going to be data at all; although, in some particular cases, we might wrongly suppose that it is (See also [8]).)

Then only data, or statements inferred from data, can be information. This theory is essentially conservative over the nature of information. We are a particular kind of sentient being and view the world through our sensory window. We observe certain things and not others. There are plenty of occupants of the world that we do not access directly through the window; for example, sub-microscopic particles like atoms, or electromagnetic waves well outside the visible range, like radio transmissions. On the face of it, this view excludes these from being any part of "information"-- they are not among the observable data, and they cannot be created by valid inference from the observable data. Proponents of this view of information may well feel that to some degree this objection is mitigated by their attraction to instruments. After all instruments extend and enhance our senses; and, for instance, electron microscopes or radiofrequency field detectors provide data about entities not immediately available to us. Maybe so; but that still does not widen the range of data enough. Science tells us that there are observable entities and properties, and unobservable ("theoretical") entities and properties; and that there are instruments to detect some unobservable entities and some observable properties; but also, crucially, that there is a huge domain of the unobservable for which no instruments of measurement exist. Yet, it is contended here, we should accept that there is information about what to us is the dark world. For DIKW, information has to rest on data (roughly, the outcome of measurements by instrument).

The intellectual backdrop of the DIKW hierarchy is positivism or operationalism, the (now thoroughly discredited) cosmological and methodological viewpoint of the 1930s [10-13]. Refined operationalism has it that concepts that cannot be defined in terms of operations (roughly, measurements by instrument) are meaningless $[10,11,13]$. Historically, the quest here was for certainty. It was thought that if concepts were defined in terms of operations, meanings could be tightly pinned down and further that the statements involving operationally defined concepts could be known for certain to be true or to be false. Supposedly, under operationalism, we could be absolutely certain of what we mean and absolutely certain as to which statements were true. 


\section{Martin Frické}

There is another worry about DIKW. Universal statements, or statistical generalizations, for example "All forty year old men eat too much" or "Most rattlesnakes are dangerous" also reach beyond the immediately observable, because only some are observed not all or most. This seems to preclude these generalizations from being information; yet surely "Most rattlesnakes are dangerous" might be information. Again, DIKW has a response. Inference from data is possible; this is what happens when, for example, information about the average temperature is produced from individual measurements of temperature. If DIKW adopts the full range of inferences permitted by inductive logic (and, perhaps, statistics or Bayesian statistics) [14, 15], maybe all or most, and similar, statements about the distantly observable, but not about the immediately observable, could be rehabilitated as information.

But widening the range of permitted inferences causes its own problems. The data that is the inferential base is intended to be true data. When the only inferences that are permitted from the base are valid inferences, ie deductively valid inferences, all the conclusions are true also. This means that all the augmented data, and all the information, the functionally promoted data, is also true. So, there is only true data and only true information. But a key property of pure inductive inference is that it is deductively invalid ie it can permit inferences from true premises to false conclusions $[14,15]$. This means that inductively derived data and information can be false. A proponent of DIKW may or may not be content with this. But either way it is a complete departure from building a pyramid on a solid base.

The dilemma is: either DIKW does not permit inductive, or similar, inference, in which case statements like "Most rattlesnakes are dangerous" cannot be information or DIKW does permit inductive inference is which case it abandons its core faith that data and information have to be rock solid true.

Moving on. The conservatism is displayed in another way. Ackoff's list of information seeking questions-- "who", "what", "where", "when", or "how many" [4] -- has a notable omission, "why". Within the DIKW schema, there is a good reason for this. To answer a why-question you have to penetrate beneath the surface, to go beyond the "data"; and that is exactly what the hierarchy approach forbids. Yet it is completely natural for inspectors of an airplane crash, for example, to search for the information telling why the accident occurred. Many, very many, information seeking questions are why-questions. And whyquestions typically are going to be answered by a mix of facts and slices from the causal nexus tailored to the context and pragmatics of the question.

Most of the foregoing criticisms can be illustrated by a simple example. The Earth goes around the Sun (as we have learned from Copernicus, Galileo, and others). That the Earth goes around the Sun is information. Yet that the Earth goes around the Sun is not data nor can it be inferred from data; it is not, and could not be, DIKW information. Further, the question of why the Earth goes around the Sun is a perfectly reasonable information seeking why-question. And its answer, in terms of initial conditions, gravitational forces, and the like, is itself information; and the answer, also, would not be considered DIKW information.

In brief, then, a good account of information should count as information rather more than the DIKW theory permits.

The DIKW theory also seems to encourage uninspired methodology. The view is that data, existing data that has been collected, is promoted to information and that information answers questions. This encourages the mindless and meaningless collection of data in the hope that one day it will be ascend to information-- pre-emptive acquisition. (And this is exactly what happens in some areas of Management Information Systems. For example, there are "data warehouses" containing data aimed at encompassing every purchase by each individual customer in every supermarket, secretly recording from the electronic scans at the check-outs, and this data awaits "mining" for information. (My response is to buy ever more eccentric combinations of goods to defeat the pattern finding algorithms, but that is another story.) There is a serious point to be made. Austin, and his colleagues, have data mined 10 million Ontario patients to "show", for instance, that Libras fracture their pelvises [16, 17], a conclusion Austin draws is

Results from data mining should be treated with skepticism [18]

No doubt many of the results of data mining are perfectly sound, and appraising data mining is not a target of this paper. The assertion being made here is just that collecting data blind is suspect methodologically.) 


\section{Martin Frické}

An analogue of the information scientist collecting data is the collection of observations by the inductivist scientist. Popper writes about that

... the belief that we can start with pure observations alone, without anything in the nature of a theory, is absurd; as may be illustrated by the story of the man who dedicated his life to natural science, wrote down everything he could observe, and bequeathed his priceless collection of observations to the Royal Society to be used as inductive evidence. This story should show us that though beetles may profitably be collected, observations may not. [19]p.46

The information scientist does not want to be collecting data hoping that it might be promoted to information. A better methodology is more top-down and just-in-time. A good theory of questions may delimit exactly the information needed to answer a particular question; and then the raising of a question will itself direct the search for information, observations, or data.

That the DIKW theory encourages uninspired methodology does not mean that it is false. It means that it is undesirable methodologically. Theories are adopted and used for a variety of purposes, in a variety of settings; and decisions regarding adoption may range over, possible orthogonal, virtues or shortcomings. Methodological weakness is one such shortcoming.

As anticipated above, the DIKW theory is reminiscent of an inductivist growth-by-accretion model of science often discussed in studies of the history and philosophy or science [19-21]. Under that, pure unprejudiced facts are determined which are generalized to the scientific theories. Inductivist history of science tells of a growth by accretion-- ever more facts have been determined, and ever more theories generalized from them, and no former "fact" is ever discarded as being wrong or false. The inductivist view has largely been abandoned and replaced by a revolution or revolution-in-permanence account of science (thanks mainly to the works of Popper and Kuhn and their followers) [19, 21]. It seems clear that even the most cherished of "pure observational facts" is open to the possibility of revision (for example, the observational fact that the Earth that we stand on is stationary, which we can all plainly see and feel, was replaced by a theory that gives the Earth a surface velocity of 1000 miles an hour, and a speed along its orbit of 68,000 miles an hour). The lesson in this for information studies is: do not suppose that there is a special category of "data" which can serve as the bedrock for all else.

So much for data and information in the DIKW hierarchy. The pyramid has no foundations.

Within philosophy, there is the distinction, explained earlier, between "know-how" and "know-that" [7, 22, 23]. All know-thats are propositional in form and, given a suitable expressing language, they can be written down and recorded or stored in data-bases. Know-hows are different. Some know-hows might be articulated as procedural rules, usually "if-then" rules. Knowing how to solve a quadratic equation, how to bid at Contract Bridge, and similar, might be conceived like this. Such rules, of course, can be written down and stored in a repository. Other know-hows do not seem to be of this kind. Knowing how to ride a bicycle is not plausibly a matter of the brain scanning, and selecting among, rules like "if you want to turn left, lean left". So, much of know-how cannot really be explicitly recorded. Within cognitive science, there is the different distinction between "procedural" and "declarative" knowledge [24, 25]. Declarative knowledge amounts to the know-thats of philosophy. But procedural knowledge is inexpressible. So someone might learn to ride of bicycle from a book by following declarative knowledge rules like "if you want to turn left, lean left" (and we wish them the best of luck with that) then, when the rider masters the skill, that declarative knowledge dissolves into the inherently inexpressible procedural knowledge know-how skill of knowing how to ride a bike. Another distinction of relevance in this context is Polanyi's distinction between tacit and explicit knowledge [26]. Tacit knowledge is the inexpressible personal how-to knowledge of domain experts; explicit knowledge is the expressible and recordable know-that knowledge that, for instance, fills books and libraries. Much of "know-how" and procedural knowledge is tacit.

Where does Ackoff, and those that favor DIKW, fit into this? Ackoff asserts

Knowledge is know-how, for example, how a system works. It is what makes possible the transformation of information into instructions. It makes control of a system possible. ([4] p.4) 


\section{Martin Frické}

So know-how is going to become instructions. In which case, it should not be the ineffable procedural knowledge of cognitive science, nor should it be philosophy's inarticulable know-how of mundane skills (like bike riding). It should not be tacit. What Ackoff attempts is not the best way to approach what he is aiming for. What is best, is to take knowledge to be know-that. Then some of those explicit know-thats will be rules or instructions (like "if the thermostat is set lower, the room will become cooler"). All of these can be recorded and stored and thus have a role central to the province of "information management, information systems and knowledge management literatures". But such know-thats do not emerge from data and information. Know-thats do not belong in DIKW. And DIKW itself should not be part of the canon of information science.

Thus far the paper has been somewhat negative in tone. Conclusions have been reached to the effect that certain, admittedly commonplace and widely accepted, positions are untenable and undesirable.

\section{Some positive theories}

What about some positive theories? Information science has an interest in data, information, knowledge, and, perhaps, wisdom. Are there some acceptable explications of these notions?

Accounts of the concept of data have a long and varied history. And those accounts often intertwine with accounts of evidence and accounts of facts. Data is "given", or a datum is "a given". As Machlup writes

Data are the things given to the analyst, investigator, or problem-solver; they may be numbers, words, sentences, records, assumptions - just anything given, no matter what form and of what origin. This used to be well known to scholars in most fields: some wanted the word data to refer to facts, especially to instrument-readings; others to assumptions. Scholars with a hypothetico-deductive bent wanted data to mean the given set of assumptions; those with an empirical bent wanted data to mean the records, or protocol statements, representing the findings of observation, qualitative or quantitative [27].

Seemingly, being a "given" really amounts to possessing two features: truth and certainty. Data is true, and data is known for certain to be true. And this leads into the traditional grand scheme of epistemology, to build all of knowledge, all of certain knowledge, on the basis of data (on the basis of sense data for the classical empiricists and logical positivists, and on the basis data of the intellect for rationalists, for example, on the data of the cogito for Descartes). But this grand vision fell to the sceptical arguments of the fallibilists: there is no such thing as certain knowledge. All knowledge is conjectural [9].

So the second feature of data fails, or needs to be modified. Data is not known for certain to be true. Data is fallible and conjectural. What about the first feature, its truth? We certainly talk of mistaken data, incorrect data, invalid data, wrong data, etc. all the time. Perhaps we record the maximum temperature for Thursday, and we write it down as 70 degrees, when really the figure should be 75 degrees. The recorded 70 degrees, for Thursday, is mistaken data. But is mistaken data still data? Strictly speaking it is not. When we discover that the temperature for Thursday is actually 75 degrees, other things being equal, we can and should correct our recorded data. The reason we do this is the supposition of success (that is why we make all the fuss about how we collect data, and make all the fuss about reliability and validity). Data is used for various purposes, to test theories and be evidence for them, to determine parameters, to answer questions, to be input for calculations, etc.. These roles pre-suppose the truth of data. Data needs to be true.

That we are fallibilists means that we never know (know for certain) that data is true, but, nonetheless, data needs to be true (see also $[8,9]$ ).

A slight detour is needed here to discuss and accommodate types. Typically when data is recorded, all sorts or kinds or types of items might be recorded (as Machlup notes). For example, when recording maximum temperature it is a number that is recorded (or, perhaps, and ordered pair of a date and a number). And we are all familiar with the standard research methods theory of scales or levels of measurement (nominal, ordinal etc.) which tells of many typical kinds of values. Now many of these 


\section{Martin Frické}

recorded values are not of the right type to be true or false. A number cannot be true or false. Apparently what is recorded is, or might be, data but those recordings cannot be true or false. So what does it mean to require that data be true? There is a transformation that needs to be made here. When values are recorded, there are statements corresponding to those values; and it is the corresponding statements that need to be true. A meteorologist may record "July $1^{\text {st }} 2007$ " "87degrees", and that date and that number are not true or false, but there is a corresponding statement, namely that on July $1^{\text {st }} 2007$ the maximum temperature was 87 degrees, and, for data, that corresponding statement needs to be true. The correspondences here are a matter of pragmatics (such as the conventions adopted for the recording process).

Data is akin to evidence. Data often is evidence. There are theories and theories of evidence, and lengthy discussion would just take us too far afield. But a central, widespread, and maybe the best current theory, of evidence is Bayesianism [28, 29]. Under Bayesianism, evidence has to be statement in form; that is, it has to be a truth bearer, it has to be true or false, and, in particular evidence has to be true. Bayesians are fallibilists. They know that there is a difficulty in knowing (for certain) what is true. So they make the requirement that evidence is assumed to be a given (relative to the context of discussion and particular Bayesian inferences).

Data is also akin to facts or (true) factual statements. Once again there are theories and theories of facts, but it is pretty mainstream to adopt a refined common sense and take it that facts are what true statements assert. Under the theory of data offered here, data is indeed similar to facts.

There are some points to be made about logical strength. The temperature at a particular time on a particular day is a singular piece of data; it is a particular fact; it is a logical atom. There might be several such atoms, and these can be combined in various ways using the standard operations of, perhaps, First Order Logic [30] ie using "and", "or", "not" etc. to make more statements. But there are also universal statements, such as "Every day the maximum temperature is above 50 degrees". Many, indeed very many, universal statements will be true (and so are candidates for being data under the characterization of data given thus far). But these universal statements are stronger, from a logical point of view, than atoms or compounds of atoms, and thus it is more difficult to be assured about their truth. Crudely, our knowledge of the universal is more fallible than our knowledge of the singular. A fallibilist would prefer to be accepting as data the truth of a judgment of the form "There is a white X" to one of the form "All Xs are white". It is possible to give a logical characterization of this feature of how strong or how weak data statements should be. Karl Popper did it with his notion of "basic statement" [31]. Basic statements, logical atoms and compounds of atoms, can be expressed by Existential-Conjunctive (EC) Logic. EC Logic is First Order Logic with its logical operators restricted to existential quantifiers and conjunction only (ie it does not have negation, implication, disjunction, and the universal quantifier). EC Logic captures concrete facts.

Unfortunately, considerations of strength and weakness, and fallibility, can also lead in the wrong direction with data. Weaker statements, perhaps ones that are vague or not overly committal, may possess greater certainty. Consider the sequence of statements,

- On 11/22/2007, in Tucson the maximum daily temperature was 65 degrees.

- On 11/22/2007, in Tucson the maximum daily temperature was greater than 30 degrees.

- On some day in 2007, in Tucson the maximum daily temperature was greater than 30 degrees.

- On some day in 2007 , somewhere in the US the maximum daily temperature was greater than 30 degrees.

The later ones are weaker than the former, they are more likely to be true, and we should be more certain of them. However, data is used for certain other purposes (answering questions, testing hypotheses, as evidence, etc.) And if statements are too weak they cannot fulfil those roles. In sum, for statements to be suitable as data they have to have Goldilock's strength: not too strong, and not too weak.

Data might be of a number of different kinds. There can be empirical data, for example about daily temperatures at a particular place and time. There can be non-empirical data, for example, the mathematical data that there are four prime numbers between 10 and 20. There can be empirical data about what might be the case (not about what is the case) for example, it can be data that were the overnight temperature in Wisconsin to be typical for a January night, the untreated water on the roads would freeze. There can be 


\section{Martin Frické}

non-empirical data in the context of fiction, for example, it is data that Sherlock Holmes lived at 221B Baker Street. And there are probably many more types of data besides. To keep the present discussion manageable, it will focus on plain empirical data about the world.

The essence of Information Science is that it deals with records, recordings, documents, inscriptions, and representational artefacts. Its historical origins are librarianship, archival studies, and the theories and practices of documentation. Nowadays research in Information Science has spread widely from its historical base to cover such areas as information seeking behaviour and many other topics. But, the core of Information Science is still the attention to external storage, storage outside the "skinbag"[32], that is, to those artefacts of preservation that form the bridge from the individual and instant of time to availability across individuals and persistence through time.

Representations of the empirical world rest on a back-story of conceptual schemes, which carve up reality, and then languages to express those conceptual scheme and the results of encounters with the world $[30,33,34]$. Natural languages are enough to achieve this (that is part of what they are for). In turn, First Order Logic (FOL) is rich enough to capture the natural languages, even with their self-reference and layers of metalanguages. Linguists, logicians, and computer scientists might use a variety of technical tools in the analysis of natural languages (lambda calculus, set theory, formal grammars, etc.), perhaps when they are looking for elegance, ease of analysis, or algorithmic efficiency. But all of that technical machinery of analysis is available to FOL ([30]p.41).

For data, the earlier part of the argument suggests that there should be a special interest in ExistentialConjunctive Logic, which is a restricted version of FOL. There is a technical result of import here. EC Logic captures exactly those statements held in ordinary computer databases.

Every database used by [SQL, Prolog, Microplanner] - as well as every commercial database, whether relational, hierarchical, or object-oriented implements the existentialconjunctive subset of logic.[30]p.163

And statements of EC logic can be put into a relational database, say, merely by adding the appropriate $\mathrm{n}$ tuple for each atom (ie for each concrete fact) [35].

In sum, the proposal on data to be defended here is that the notion of data, of interest to Information Science, is that of anything recordable in a database in a semantically and pragmatically sound way. The semantics require that the recordings be understood as true or false statements. The pragmatics require that we favor recording what seem to be concrete facts ie singular and relatively weak statements, and that interpreted recordings be true statements (and we have to use conjectures on this).

How does this differ from the DIKW account of data? Data can be more than the mere "observable", and it can be more than the pronouncements of "instruments". There are contexts, conventions, and pragmatics at work. In particular circumstances, researchers might regard some recordings as data which report matters that are neither observable nor determinable by instrument.

What about information? Information can be, and has been, construed to be

- knowledge, personal or public,

- the physical manifestation of knowledge,

- a state or structure transformer,

- knowledge or belief new to subject,

- a member of the data-information-knowledge-(wisdom/understanding) hierarchy,

- a construct in thermodynamics,

- entropy or negentropy,

- reduction in uncertainty,

- signal information,

- content or semantic information,

- truthlike information, 


\section{Martin Frické}

- $\quad$ patterns,

and, many more things besides [2, 36-38].

As Floridi writes

Information is notoriously a polymorphic phenomenon and a polysemantic concept so, as an explicandum, it can be associated with several explanations, depending on the level of abstraction adopted and the cluster of requirements and desiderata orientating a theory [39].

Working broad brush, these accounts of information can be characterized as being syntactic or semantic. Syntactic information, such as Shannon's signal information, Chaitin's Kolmogorov complexity, thermodynamic entropy, Fisher information etc., are certainly important for Information Science [40-42]. In particular, the physical transmission of encoded information, its compression and error correction via Huffman trees, Hamming codes and the like, have their theoretical foundation with Shannon [41]. But in the context of the DIKW pyramid, with the desire to talk about data, knowledge, and wisdom, syntactic information is not the concept in use. The DIKW pyramid is not about juggling and permuting inscriptions, or their electronic counterparts, in an accurate and efficient way. Instead the concept employed is semantic information. This is the concept where attention is paid to the meaning and truth, and other semantic properties, of the recorded marks.

Within accounts of semantic information there are many theories and a number of live issues. Need information be true? Is misinformation and disinformation real information? Need information be new to the User? Must someone be "informed" by it, for it to be information? There are open questions about which reasonable researchers can disagree. Even so, a proposal can be placed on the table. The focus of interest in this context is both Information Science and data. Librarians often use "knowledge" and "information" as synonyms, and they need not be widely wrong to do so. Information can be taken to be the recorded counterpart of true propositions ie weak knowledge. While the standard justified-true-belief account of personal knowledge, and justified-true-(community-accepted) account of public knowledge, are absolutely central and widespread within traditional philosophy [9], they are by no means universal with modern philosophers. Many contemporary epistemologists make a distinction between strong and weak knowledge, Goldman is one example [43]. Strong knowledge covers justified-true-beliefs and justifiedtrue-(community-accepted)-statements. Weak knowledge is like strong knowledge except that the justification component is omitted. Thus, weak personal knowledge consists of beliefs which are true, and weak impersonal knowledge consists of community held views which are true. The concept of weak personal or public knowledge, in its recorded form, is suitable as a view of information.

The interim conclusions are these. There are many different senses of "information". There are even many different senses of "information" in use in Information Science. It is not the case the one of these senses is good, and all purpose, and the others deficient. But, both in Information Science and elsewhere, there are different problems and different contexts where these different notions of information come into play. As Shannon wrote

The word "information" has been given different meanings by various writers in the general field of information theory. It is likely that at least a number of these will prove sufficiently useful in certain applications to deserve further study and permanent recognition. It is hardly to be expected that a single concept of information would satisfactorily account for the numerous possible applications of this general field.[44]p.180

And, when the focus is on DIKW, so-called "weak knowledge" may prove suitable as an account of information.

What, then, would be the relationship between data and information? All data is information. However, there is information that is not data. Almost all of science is information, but, in most contexts, it is not data. That the Earth rotates on its axis and orbits the sun is information, but not, for most purposes, data. Information can range much more widely than data; it can be much more extensive than the given. The point can be made solely in terms of logic. Data typically is expressed by Existential-Conjunctive logic, information requires the full First Order Logic; the latter cannot even be expressed in its entirety by the 


\section{Martin Frické}

former; and, in particular, some statements in the latter amount to information and they cannot be inferred from the former. [Supposing that they can is the central mistake of the DIKW pyramid.]

How does this differ from the DIKW account of information? Information is both more extensive than data and many instances of it are logically stronger than data. Information is irreducible to data.

For an account of knowledge, as explained above, Information Science should use a propositional account of knowledge ie knowledge-that, and then use the notion of weak knowledge. This makes knowledge and information synonymous. Knowledge and information collapse into each other.

How does this differ from the DIKW account of knowledge? DIKW sees knowledge as know-how; and, in turn, this tends to make knowledge inarticulable and not recordable. In contrast, weak-knowledgethat is knowledge-that and it is articulable and recordable,

That leaves wisdom. The concept of wisdom certainly occupied the ancient Greek philosophers, such as Plato and Aristotle; although it has not been a popular topic of discussion in recent times. There seem to be several different strands to wisdom [45]. A wise person needs to have an understanding of the epistemic status of what he or she knows ie they have to be a fallibilist-Socrates was considered wise largely because all he knew was that he knew nothing. Then a wise person has to know, fallibly, plenty. A person that genuinely knows little or nothing, a person with an empty head, is not a wise person. Then this wide knowledge has to be of a certain kind, a kind that applies to the many and varied problems of life. A person may have encyclopaedic knowledge of the facts and figures relating to the countries of the world; but that knowledge, of itself, will not make that person wise. The wide knowledge has to be applicable to tricky problems of an ethical and practical kind, of how to act.

Wisdom is not just one type of knowledge, but diverse. What a wise person needs to know and understand constitutes a varied list: the most important goals and values of life - the ultimate goal, if there is one; what means will reach these goals without too great a cost; what kinds of dangers threaten the achieving of these goals; how to recognize and avoid or minimize these dangers; what different types of human beings are like in their actions and motives (as this presents dangers or opportunities); what is not possible or feasible to achieve (or avoid); how to tell what is appropriate when; knowing when certain goals are sufficiently achieved; what limitations are unavoidable and how to accept them; how to improve oneself and one's relationships with others or society; knowing what the true and unapparent value of various things is; when to take a long-term view; knowing the variety and obduracy of facts, institutions, and human nature; understanding what one's real motives are; how to cope and deal with the major tragedies and dilemmas of life, and with the major good things too. [46]

And the wise person must not only have wide appropriate knowledge, but they must act in accordance with the knowledge they have. For example, a person may have extensive practical knowledge including some knowledge of the foolhardiness of climbing into a tiger's cage - if they then attempt visits with tigers, such exploits will disqualify them from the sobriquet "wise" (perhaps among other consequences).

The DIKW account of wisdom, in its Ackoff version, is reasonably in harmony with this. Ackoff, and his immediate followers, were systems theorists, they were control theorists. Knowledge was know-how, know how to control the systems. Then wisdom was merely a matter of using that practical know how to achieve appropriate ends. That is a reasonably defensible view-it just does not want to be embedded in the DIKW hierarchy.

\section{References}




\section{Martin Frické}

[1] J. Rowley, The wisdom hierarchy: representations of the DIKW hierarchy, Journal of Information Science 33(2) (2007) 163-180.

[2] M.J. Bates, Information and knowledge: an evolutionary framework for information science, Information Research 10(4) (2005) paper 239.

[3] J. Listserv. DIKW. Jesse Listserv 14.52005 [cited Message posted to the Jesse electronic mailing list, archived at http://listserv.utk.edu/cgibin $/$ wa? $A 2=$ ind $0512 \& \mathrm{~L}=$ jesse $\& \mathrm{~T}=0 \& \mathrm{X}=0 \mathrm{CF} 5 \mathrm{BF} 3 \mathrm{EF} 0390 \mathrm{CDC} 08 \& \mathrm{P}=1733]$.

[4] R.L. Ackoff, From data to wisdom, Journal of Applied Systems Analysis 16 (1989) 3-9.

[5] M.J. Adler, A Guidebook to Learning : for a Lifelong Pursuit of Wisdom. (Macmillan, New York, 1986).

[6] M. Zeleny, Management support systems: towards integrated knowledge management, Human Systems Management 7(1) (1987) 59-70.

[7] G. Ryle, Knowing how and knowing that. In: G. Ryle (ed.), Collected Papers, Vol II: Collected Essays (1929-1968), (Barnes \& Noble, Inc., New York, 1946).

[8] S. Haack, A fallibilist among the cynics, Skeptical Inquirer 23(1) (1999) 47-50.

[9] A. Musgrave, Common Sense, Science, and Scepticism : a Historical Introduction to the Theory of Knowledge. (Cambridge University Press, Cambridge, 1993).

[10] P.W. Bridgman, The Logic of Modern Physics. (Macmillan, New York, 1927).

[11] P.W. Bridgman, The Nature of Physical Theory. (Princeton University Press, Princeton, 1936).

[12] H. Feigl. Positivism in the Twentieth Century (Logical Empiricism). Dictionary of the History of Ideas 1974 5/1/2003 [cited 2008 February 17]; Available at: http://etext.lib.virginia.edu/cgilocal/DHI/dhiana.cgi?id=dv3-69.

[13] C.G. Hempel, A logical appraisal of operationalism, Scientific Monthly 79 (1954) 215-220.

[14] I. Hacking, Introduction to Probability and Inductive Logic. (Cambridge University Press, Cambridge, 2001).

[15] B. Skyrms, Choice and Chance: An Introduction to Inductive Logic 4th revised ed. (Wadsworth, Belmont, CA, 2000).

[16] P.C. Austin and M.A. Goldwasser, Pisces did not have increased heart failure: Data-driven comparisons of binary proportions between levels of a categorical variable can result in incorrect statistical significance levels, Journal of Clinical Epidemiology 61(3) (2008) 295-300.

[17] P.C. Austin, et al., Testing multiple statistical hypotheses resulted in spurious associations: a study of astrological signs and health, Journal of Clinical Epidemiology 59(9) (2006) 871-2.

[18] L. Dye. Do Libras Live Longer? 2007 [cited 2008 March 20 2008]; Available at: http://abcnews.go.com/Technology/Story?id=2890150\&page=1.

[19] K.R. Popper, Conjectures and Refutations. (Routledge and Kegan Paul, London, 1963).

[20] C.G. Hempel, Philosophy of Natural Science. (Prentice-Hall, Englewood Cliffs, NJ, 1966).

[21] T.S. Kuhn, The Structure of Scientific Revolutions 2nd ed. ( University of Chicago Press, Chicago, 1962).

[22] D. Carr, The logic of knowing how and ability, Mind 88 (1979) 394-409.

[23] P. Snowdon, Knowing How and Knowing That: A Distinction Reconsidered, Proceedings of The Aristotelian Society 104 (2004) 1-29.

[24] J.R. Anderson, Language, Memory, and Thought. (Erlbaum, Hillsdale, NJ, 1976).

[25] A. Newell, Human Problem Solving. (Prentice-Hall, Englewood Cliffs, NJ, 1972).

[26] M.E. Polanyi, Personal Knowledge: towards a Post-Critical Philosophy (Routledge and Kegan Paul, London, 1958). 


\section{Martin Frické}

[27] F. Machlup, Semantic quirks in studies of information. In: F. Machlup and U. Mansfield (ed.), The Study of Information: Inter-disciplinary Message, (Wiley, New York, NY., 1983).

[28] C. Howson and P. Urbach, Scientific Reasoning : the Bayesian Approach 2nd ed. (Open Court, Chicago, 1993).

[29] E.T. Jaynes, Probability Theory : the Logic of Science / E.T. Jaynes, ed. G.L. Bretthorst. (Cambridge University Press, Cambridge, UK, 2003).

[30] J.F. Sowa, Knowledge Representation: Logical, Philosophical, and Computational Foundations. (Brooks/Cole, Pacific Grove, CA, 2000).

[31] K.R. Popper, The Logic of Scientific Discovery. (Hutchinson, London, 1959).

[32] A. Clark, Natural-Born Cyborgs: Minds, Technologies, and the Future of Human Intelligence. (Oxford University Press, Oxford, 2003).

[33] P. Tichy, An approach to Intensional Analysis, Nous 5(3) (1971) 273-297.

[34] P. Tichy, The analysis of natural language. In: V. Svoboda, B. Jesperson \& C. Cheyne (ed.), Pavel Tichy's Collected Papers in Logic and Philosophy, (University of Otago Press, Dunedin, New Zealand, 2004).

[35] E.F. Codd, A relational model of data for large shared data banks, Communications of the ACM 13(6) (1970) 377-387.

[36] M.J. Bates, Fundamental forms of information, Journal of the American Society for Information Science and Technology 57(8) (2006) 1033-1045.

[37] N.J. Belkin, Information concepts for Information Science, Journal of Documentation 34(1) (1978) 55-85.

[38] M. Frické, Information using likeness measures, Journal of the American Society for Information Science 48(10) (1997) 882-892.

[39] L. Floridi, Information. In: L. Floridi (ed.), The Blackwell Guide to the Philosophy of Computing and Information, (Blackwell, Oxford - New York, 2004).

[40] G.J. Chaitin, Information, Randomness \& Incompleteness : Papers on Algorithmic Information Theory. World Scientific Series in Computer Science. Vol. 8. (Teaneck, NJ, USA, Singapore, 1987).

[41] J.R. Pierce, An Introduction to Information Theory: Symbols, Signals \& Noise 2nd, rev. ed. (Dover Publications, New York, 1980).

[42] C.E. Shannon and W. Weaver, The Mathematical Theory of Communication. (University of Illinois Press, Urbana, 1949).

[43] A.I. Goldman, Knowledge in a Social World. (Clarendon Press, Oxford, 1999).

[44] C.E. Shannon, Collected Papers, ed. N.J.A. Sloane and A.D. Wyner. (IEEE Computer Society Press, Los Alamos, Ca:, 1993).

[45] S. Ryan. Wisdom. Stanford Encylopedia of Philosophy 2007 1/8/2008 [cited 2007 November 22]; Available at: http://plato.stanford.edu/entries/wisdom/.

[46] R. Nozick, What is wisdom and why do philosophers love it so? In: R. Nozick (ed.), The Examined Life, (Touchstone Press, New York, 1989). 